ARTIKEL

PENGABDIAN KEPADA MASYARAKAT

PERAN KELUARGA DALAM MENUMBUHKAN PERILAKU POSITIF ANAK MELALUI PENDEKATAN BEHAVIOR

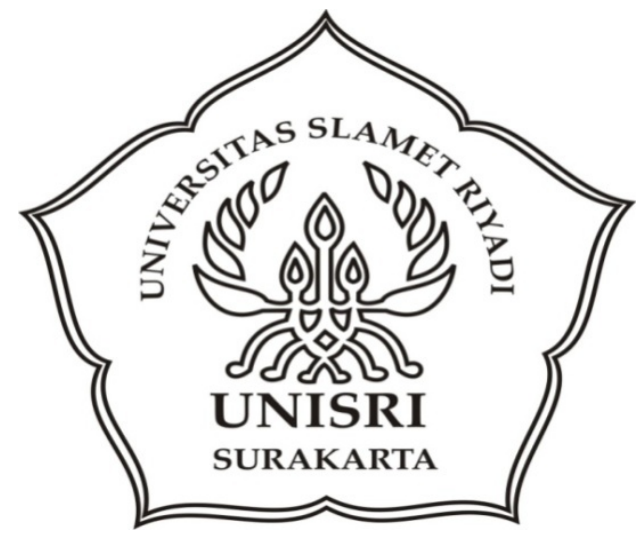

TIM PENGUSUL

Ahmad Jawandi, S.Pd, M.Pd

Eko Adi Putro, S.Pd., M.Pd

Alfridus Naisoko

FAKULTAS KEGURUAN DAN ILMU PENDIDIKAN

UNIVERSITAS SLAMET RIYADI SURAKARTA

JANUARI 2019 


\title{
PERAN KELUARGA DALAM MENUMBUHKAN PERILAKU POSITIF ANAK MELALUI PENDEKATAN BEHAVIOR
}

\author{
Oleh : \\ Ahmad Jawandi dan Eko Adi Putro \\ Program Studi Bimbingan dan Konseling \\ Fakultas Keguruan dan Ilmu pendidikan, Universitas Slamet Riyadi, \\ Jl. Sumpah Pemuda No.18 Surakarta, Jawa Tengah \\ ahmadjawandi@gmail.com
}

\begin{abstract}
Family becomes the smallest social unit in a society. The socialization process was first carried out in the family. Educate children to get to know children and how to treat children according to their needs and development. By recognizing and understanding their children, parents as educators in the family will be able to increase their potential as optimally as possible, especially in forming positive behaviors. Behavior is any form of action taken or planned. While positive behavior is an action that is in accordance with the character, culture, norms and noble values in the community. In order for children to grow and develop optimally, the family or parents need to increase their role. Along with the times and the assimilation of culture in the era of globalization of positive behavior in children such as manners, tolerance, caring for others and respect for others is increasingly lost. The effort that can be taken to develop positive behavior of children in the family environment is through a behavioral approach. The target of service is the Beneficiary Family (KPM) of the Hope Family Program in Wonosegoro District. The purpose of this community service activity is to provide training methods in enhancing family roles to foster positive behavior through a behavioral approach. The method used in this community service is the behaviorism approach in increasing family roles to form positive behavior. In this behavior approach uses several techniques, namely modeling techniques, reinforcement techniques and Asertive training techniques. The implementation of community service carried out with seminars and training through lectures, discussions and brainstorming, questions and answers, and direct practice. The implementation of the behavioral approach training as an effort to improve the family's role in forming positive behavior was Carried out in four meetings. The expected result of community service is the realization of parents' understanding of the importance of the role of the family in fostering positive behaviors of children that are applied in daily life through a behavioral approach.
\end{abstract}

Keywords: Family Role, Positive Behavior, Behavior Approach

\section{PENDAHULUAN}

Perkembangan teknologi dan informasi mempunyai implikasi yang sangat kompleks bagi masyarakat. Salah satunya mempersiapkan anak untuk dapat menyesuaikan dengan tuntutan kehidupan di masa kini dan masa yang akan datang. Upaya orang tua untuk mendidik dan membesarkan anaknya dengan segala fasilitas pendidikan merupakan langkah tepat. Orang tua memiliki peran sentral untuk terus-menerus membangun semangat atas kesadaran akan pentingnya pendidikan di lingkungan keluarga dan masyarakat. Anak yang dibesarkan di lingkungan keluarga yang terdidik, memiliki peluang yang besar untuk tumbuh dengan baik.

Keluarga menjadi unit sosial terkecil yang ada dalam sebuah masyarakat. Proses sosialisasi pertama kali dilakukan dalam keluarga. Pakem-pakem benar atau salahnya dalam suatu masyarakat akan diajarkan orang 
tua kepada anaknya. Mendidik anak bermuara dari mengenal anak dan cara memperlakukan anak sesuai kebutuhannya dan perkembangannya. Keluarga merupakan pusat pendidikan yang utama bagi anak. Oleh sebab itu keluarga memiliki peran penting dalam membentuk perilaku positif anak sedini mungkin. Perilaku merupakan Segala bentuk tindakan yang dilakukan atau direncanakan (Sears,dkk, 2006). Sedangkan perilaku positif adalah tindakan yang sesuai dengan karakter, budaya, norma dan nilai-nilai luhur dimasyarakat.

Seiring perkembangan zaman dan asimilasi budaya di era globalisasi perilaku positif pada anak seperti sopan santun, tenggang rasa, peduli sesama dan menghormati orang lain semakin hilang. Anak merupakan tunas muda harapan bangsa, dan pemimpin pada masa yang akan datang. Oleh karena itu jika anak tidak mempunyai kesiapan dan tidak dapat memberikan sumbangan dalam gelanggang kehidupan negara dan bangsa, niscaya akan hancur leburlah kehidupan bangsa kita. Dengan demikian, kedudukan remaja sebagai angkatan muda adalah vital. Kedudukan ini merupakan kehormatan yang besar, tetapi juga membawa tugas yang berat.

Banyak keluarga atau orang tua yang belum menyadari bahwa pendidikan yang diberikan di rumah kadang tidak sesuai dan searah sebagaimana yang diberikan di sekolah. Akibatnya kadang anak mengalami kegagalan dalam penyesuaian. Sebagian orang tua merasa terpukul atau kecewa jika anaknya mengalami kegagalan, baik di bidang studi, karier, atau hubungan sosial di masyarakat. Keluarga atau orang tua merasa kesulitan dalam memahami, dan membimbing, karena mereka kurang mengerti cara yang efektif dalam mendidik anak, lebihlebih pada usia remaja.

Kendala serupa juga ditemukan oleh peneliti pada Keluarga Penerima Manfaat (KPM) yang tergabung dalam Program Keluarga Harapan Kecamatan Wonosegoro, Kabupaten Boyolali. Berdasarkan wawancara yang dilakukan peneliti kepada pendamping PKH dan beberapa KPM Kecamatan wonosegoro diperoleh beberapa informasi bahwa banyak orang tua yang mengeluhkan terkait perilaku anaknya yang kurang baik dan mengarah pada kenakalan; asumsi yang masih salah pada orang tua bahwa pendidikan moral dan perilaku hanya dilakukan disekolah; pemahaman yang masih kurang terkait cara yang tepat dalam membentuk perilaku positif dilingkungan keluarga; sebagian besar orang tua anggota $\mathrm{PKH}$ memiliki pendidikan yang kurang dan membutuhkan bimbingan dan informasi tentang pola asuh orang tua yang tepat.

Upaya yang dapat ditempuh untuk mengembangkan perilaku positif anak dilingkungan keluarga adalah menggunakan pendekatan behavior. Teori behavioristik adalah teori perkembangan perilaku, yang dapat diukur, diamati dan dihasilkan oleh respons pelajar terhadap 
rangsangan. Tanggapan terhadap rangsangan dapat diperkuat dengan umpan balik positif atau negatif terhadap perilaku kondisi yang diinginkan. Hukuman kadang-kadang digunakan dalam menghilangkan atau mengurangi tindakan tidak benar, diikuti dengan menjelaskan tindakan yang diinginkan.

Salah satu alasan pemilihan pendekatan behavior adalah karena sederhana dan cukup mudah dilakukan oleh orang tua. Salah satunya adalah teknik modeling, yaitu orang tua menjadi suri tauladan yang memberikan contoh-contoh bagaiman berperilaku yang baik dilingkungan keluarga. Cara lain adalah dengan menggunakan penguatan positif. Kegiatan apapun yang dilakukan anak serta bagaimanapun juga hasilnya berilah penghargaan dan apresiasi yang positif. Tidak ada hal yang sempurna di dunia ini maka berilah pujian serta komentar yang positif dan membangun agar anak lebih semangat berkarya dan tidak alergi terhadap kritikan. Baik disadari oleh orang tua maupun tidak, pada dasarnya anak selalu ingin menunjukkan hasil karya mereka kepada orang tua. Sekecil apapun hasil yang mereka lakukan, mereka ingin pengakuan dari orang tua. Diperlukan kejelian dan sikap bijak orang tua saat anakanak berusaha menunjukkan hasil karya mereka. Walaupun tampak berantakan cara membereskan mainan atau tempat tidur mereka, hargailah upaya yang telah mereka lakukan dan berikan komentar positif sambil mengajak anak-anak untuk lebih merapikannya. Hal kecil seperti ini akan meningkatkan rasa bangga dan kepercayaan diri mereka serta melatih untuk melakukan kegiatan dengan lebih tepat. Dan juga tidak ada salahnya jika diberi reward sederhana dengan dibuatkan makanan atau minuman istimewa yang mereka sukai. Ubahlah cara pandang sebagai orang tua dengan memberikan pujian dan motivasi untuk anak lebih semangat belajar.

Bertitik tolak dari fenomena di atas maka keluarga atau orang tua perlu meningkatkan perannya dalam membentuk perilaku positif pada anak, serta memiliki keterampilan bagaimana menjadi orang tua yang efektif bagi anaknya. Sehingga penulis akan melakukan pelatihan tentang peran keluarga dalam menumbuhkan perilaku positif melalui pendekatan behavior pada Keluarga Penerima Manfaat (KPM) Program Keluarga Harapan Kecamatan Wonosegoro, Kabupaten Boyolali.

\section{METODE PELAKSANAAN}

Metode yang digunakan dalam pengabdian masyarakat ini adalah behaviorisme sebagai pendekatan dalam meningkatkan peran keluarga untuk membentuk perilaku positif. Dalam pendekatan behavior ini menggunakan beberapa teknik yaitu teknik modeling, teknik Reinforcement dan teknik Asertive training . Pendekatan behavior ini memiliki beberapa tahapan yaitu menjalin hubungan yang baik dengan peserta, mengidentifikasi 
permasalahan terkait pola asuh dan perilaku malasuai / maladaptive / negative pada anak, pengubahan pola pikir orang tua tentang pentingnya peran keluarga, praktik penerapan teknik-teknik behavior, pengubahan perilaku dan evaluasi kegiatan.

Pelaksanaan pengabdian kepada masyarakat ini, dilaksanakan dengan seminar dan pelatihan melalui ceramah, diskusi dan ramu pendapat (brain storming), tanya jawab, serta praktik pendekatan behavior.

Pelaksanaan pelatihan pendekatan behavior sebagai upaya dalam meningkatkan peran keluarga untuk membentuk perilaku positif dilakukan sebanyak 4 kali pertemuan.

Kriteria keberhasilan,dilihat dari banyaknya peserta dan antusias mereka dalam mengajukan pertanyaan dan tanggapan serta praktik "Metode-metode dalam pendekatan behavior”. Indikator pencapaian tujuan, dilihat dari penguasaan peserta terhadap materi yang disampaikan terwujud dengan pernyataan senang dan puas sesudah mendapatkan materi. Peserta menyatakan akan melaksanakan kita-kiat bagaimana meningkatkan peran keluarga dalam menumbuhkan perilaku positif.

\section{HASIL DAN PEMBAHASAN}

Pelaksanaan pelatihan pendekatan behavior sebagai upaya dalam meningkatkan peran keluarga untuk membentuk perilaku positif dilakukan sebanyak 4 kali pertemuan. Adapun pelaksanaannya dalam setiap pertemuan dapat dijelaskan sebagai berikut :

\section{Pertemuan pertama}

Pertemuan pertama dilaksanakan di rumah Ibu Karni pada tanggal 10 Januari 2019 yang dimulai pukul 10.30. Dalam pemberian treatment dibagi menjadi tiga tahap yang dapat dijabarkan sebagai berikut:

(a) Persiapan

Pertemuan diawali dengan salam pembuka, perkenalan dan presensi peserta. Selanjutnya mengkondisikan peserta dalam situasi yang menyenangkan (pembentukan good rapport). Pada saat pertemuan beberapa anggota kelompok terlihat tegang, gugup, kaku dan agak malu. Selanjutnya narasumber menjelaskan maksud dan tujuan pelatihan pendekatan behavior sebagai upaya dalam meningkatkan peran keluarga untuk membentuk perilaku positif. Setelah anggota kelompok merasa nyaman, peneliti melanjutkan kegiatan dengan berdoa bersama.

(b) Pelaksanaan Kegiatan

Pada pertemuan pertama, narasumber memberikan materi tentang pentingnya peran keluarga dalam menumbuhkan perilaku positif anak. Tujuannya untuk menumbuhkan kesadaran orang tua tentang pentingnya menciptakan lingkungan keluarga yang kondusif untuk perkembangan anak khususnya dalam membentuk perilaku positif. Proses selanjutnya melakukan diskusi, yaitu beberapa anggota kelompok menyampaikan hasil pemikirannya dan dilanjutkan tanya jawab yang dipandu oleh narasumber.

(c) Penutup

Masuk pada tahap pengakhiran anggota kelompok menyampaikan apa saja yang 
diperoleh dari proses kegiatan. Narasumber membuat simpulan akhir sebagai penguatan supaya anggota kelompok dapat mengerti dan paham tentang materi yang dibahas. Evaluasi dalam kegiatan ini berupa kesan dan pesan dari peserta yang merasa puas dan senang bisa mendapat pengetahuan dari kegiatan pelatihan pendekatan behavior sebagai upaya dalam meningkatkan peran keluarga untuk membentuk perilaku positif.

\section{Pertemuan Kedua}

Pertemuan kedua dilaksanakan di rumah Ibu Nunuk pada tanggal 12 Januari 2019 yang dimulai pukul 12.00. Dalam pemberian treatment dibagi menjadi tiga tahap yang dapat dijabarkan sebagai berikut:

\section{(a) Persiapan}

Pertemuan diawali dengan salam pembuka dan presensi peserta. Selanjutnya mengkondisikan peserta dalam situasi yang menyenangkan (pembentukan good rapport). Selanjutnya narasumber menjelaskan maksud dan tujuan kegiatan. Setelah anggota kelompok merasa nyaman, peneliti melanjutkan kegiatan dengan berdoa bersama.

(b) Pelaksanaan Kegiatan

Pertemuan kedua memberikan materi tentang pendekatan behavior dengan teknik modeling untuk menumbuhkan perilaku positif anak. Melalui modeling orang tua diminta untuk menjadi model / figur yang akan dijadikan tauladan oleh anak. Sehingga orang tua akan dilatih untuk memberikan contoh-contoh perilaku positif pada anak mulai dari hal yang sangat sederhana seperti bagaimana cara berbicara dengan orang yang lebih tua, sopan santun dalam keluarga, dan etika bergaul. Secara bergantian peserta diminta untuk mempraktekkan sebagai model yang melakukan perilaku positif dalam lingkungan keluarga.

(c) Penutup

Pada tahap pengakhiran anggota kelompok menyampaikan apa saja yang diperoleh dari proses kegiatan. Narasumber membuat simpulan akhir sebagai penguatan supaya anggota kelompok dapat mengerti dan paham tentang materi yang dibahas. Evaluasi dalam kegiatan ini berupa kesan dan pesan dari peserta yang merasa puas dan senang

\section{Pertemuan Ketiga}

Pertemuan ketiga dilaksanakan di rumah Ibu Tukinah pada tanggal 14 Januari 2019 yang dimulai pukul 13.00. Dalam pemberian treatment dibagi menjadi tiga tahap yang dapat dijabarkan sebagai berikut:

(a) Persiapan

Pertemuan dibuka dengan ice breaking, presensi dan pengkondisian peserta dalam situasi yang menyenangkan. Narasumber dengan sikap terbuka dan hangat menyambut kehadiran anggota kelompok, kemudian mengucapkan salam serta memimpin berdoa sebelum melakukan kegiatan berikutnya.

(b) Pelaksanaan Kegiatan

Pertemuan ketiga memberikan materi tentang pendekatan behavior dengan teknik Reinforcement untuk menumbuhkan perilaku positif anak. Kegiatan apapun yang dilakukan 
anak serta bagaimanapun juga hasilnya harus diberi penghargaan dan apresiasi yang positif. Hal kecil seperti ini akan meningkatkan rasa bangga dan kepercayaan diri mereka serta melatih untuk melakukan kegiatan dengan lebih tepat. Sehingga orang tua dilatih untuk memberikan Reinforcement sederhana seperti memuji anak ketika melakukan perbuatan yang baik. Beberapa peserta diminta untuk menampilkan kalimat-kalimat pujian untuk anaknya.

(c) Penutup

Pada tahap pengakhiran anggota kelompok menyampaikan apa saja yang diperoleh dari proses kegiatan. Narasumber membuat simpulan akhir sebagai penguatan supaya anggota kelompok dapat mengerti dan paham tentang materi yang dibahas. Evaluasi dalam kegiatan ini berupa kesan dan pesan dari peserta yang merasa puas dan senang

\section{Pertemuan Keempat}

Pertemuan keempat dilaksanakan di Rumah Ibu Nunuk pada tanggal 17 Januari 2019 yang dimulai pukul 10.00. Dalam pemberian treatment dibagi menjadi tiga tahap yang dapat dijabarkan sebagai berikut:

(a) Persiapan

Pertemuan dibuka dengan ice breaking, presensi dan pengkondisian peserta dalam situasi yang menyenangkan. Narasumber dengan sikap terbuka dan hangat menyambut kehadiran anggota kelompok, kemudian mengucapkan salam serta memimpin berdoa sebelum melakukan kegiatan berikutnya.

(b) Pelaksanaan Kegiatan
Pertemuan keempat memberikan materi tentang pendekatan behavior dengan teknik Asertive training untuk menumbuhkan perilaku positif anak. Teknik asertif membantu orang tua untuk mengekspresikan perasaan dan pikiran yang ditekankan terhadap anak secara lugas tampa agresif. Latihan sederhana diberikan pada orang tua dengan menampilkan ekspresi dan sikap yang hangat dan menyenangkan kepada anak, seperti tersenyum, ekspresi bahagia, belaian dan pelukan. Dalam kegiatan pelatihan orang tua diminta melakukan simulasi dengan cara berpasangan dua orang dan saling berhadapan, kemudian saling berinteraksi dengan menggunakan bahasa yang halus, tersenyum, ekspresi bahagia.

(c) Penutup

Pada tahap pengakhiran anggota kelompok menyampaikan apa saja yang diperoleh dari proses kegiatan. Narasumber membuat simpulan akhir sebagai penguatan supaya anggota kelompok dapat mengerti dan paham tentang materi yang dibahas. Evaluasi dalam kegiatan ini berupa kesan dan pesan dari peserta yang merasa puas dan senang Pada setiap pertemuan narasumber selalu melakukan evaluasi proses dan hasil. Evaluasi proses dilakukan dengan bertanya secara langsung tentang kesan, pesan, dan apa yang diperoleh selama proses pelaksanaan kegiatan. Sedangkan evaluasi hasil dilihat melalui observasi langsung terkait pemahaman masyarakat yang ditunjukkan dengan perubahan sikap dan perilaku. Dari 
perubahan tersebut dapat disimpulkan bahwa pendekatan behavior dapat meningkatkan peran keluarga untuk membentuk perilaku positif anak.

\section{KESIMPULAN}

Berdasarkan pelaksanaan program pengabdian kepada masyarakat dapat disimpulkan bahwa pendekatan Behavior mampu mengoptimalkan peran keluarga dalam membentuk perilaku positif. Hal ini dibuktikan dengan penguasaan peserta terhadap materi yang disampaikan terwujud dengan pernyataan senang dan puas sesudah mendapatkan materi. Peserta berjanji akan melaksanakan kita-kiat bagaimana meningkatkan peran keluarga dalam menumbuhkan perilaku positif. Keberhasilan juga dilihat dari banyaknya peserta dan antusias mereka dalam mengajukan pertanyaan dan data hasil observasi yang menunjukkan adanya perubahan sikap dan perilaku yang lebih positif.

\section{SARAN}

Berdasarkan simpulan yang sesuai dengan hasil penelitian, maka dapat diajukan beberapa saran kepada masing-masing pihak sebagai berikut:

1. Bagi Universitas: Universitas hendaknya menyediakan akomodasi yang memadai untuk kelancaran pelaksanaan kegiatan pengabdian kepada masyarakat serta menjalin kerjasama dengan berbagai pihak dalam membangun masyarakat yang lebih baik.

2. Bagi Mitra: a. Orang tua hendanya memahami berbagai kebutuhan perkembangan anak, khususnya peran keluarga dalam membentuk pribadi dan perilaku anak.

b. Pendekatan Behavior hendaknya dilakukan orang tua dalam lingkungan keluarga untuk membentuk perilaku positif anak.

\section{DAFTAR PUSTAKA}

Corey. G. (2013). Teori dan Praktek Konseling dan Psikoterapi. Bandung : Refika Aditama.

Erford, B. T. 2015. 40 Techniques Every Counselor Should Know (2nd eds). New Jersey: Pearson Education, Inc

Farozin \& Kartika N F. 2004. Pemahaman Tingkah Laku. Yogyakarta : Rineka Cipta

Garry Martin \& Joseph Pear. 2015. Modifikasi Perilakau (makna dan penerapannya). Yogyakarta : Pustaka Pelajar

Gibson dan Mitchell. 2011. Bimbingan dan Konseling. Yogyakarta : Pustaka Pelajar

Samuel T. Glading. 2012. Konseling: Profesi yang Menyeluruh. Jakarta : Indeks

Sears. 2006. Psikologi Sosial. Jakarta : erlangga. 